\title{
Autologous Dendritic Cell Vaccine ACT2001
}

National Cancer Institute

\section{Source}

National Cancer Institute. Autologous Dendritic Cell Vaccine ACT 2001. NCI Thesaurus.

Code C121856.

A cell-based cancer vaccine composed of autologous, immature dendritic cells (DCs), with potential immunostimulating and antineoplastic activities. Upon leukapheresis, immature DCs are isolated and re-administered intra-tumorally. The immature DCs internalize and process the tumor-associated antigens (TAAs), migrate to the lymphatic system, and then expose the immune system to the TAAs. This induces a specific cytotoxic T-lymphocyte (CTL) response against the cancer cells leading to tumor cell lysis. 